\title{
Wave-turbulence scaling in the ocean mixed layer
}

\author{
G. Sutherland $^{1}$, B. Ward ${ }^{1}$, and K. H. Christensen ${ }^{2}$ \\ ${ }^{1}$ School of Physics and Ryan Institute, National University of Ireland, Galway \\ ${ }^{2}$ Norwegian Meteorological Institute, Oslo, Norway \\ Correspondence to: B. Ward (bward@nuigalway.ie)
}

Received: 24 September 2012 - Published in Ocean Sci. Discuss.: 18 December 2012

Revised: 16 May 2013 - Accepted: 11 June 2013 - Published: 8 July 2013

\begin{abstract}
Microstructure measurements were collected using an autonomous freely rising profiler under a variety of different atmospheric forcing and sea states in the open ocean. Here, profiles of turbulent kinetic energy dissipation rate, $\epsilon$, are compared with various proposed scalings. In the oceanic boundary layer, the depth dependence of $\epsilon$ was found to be largely consistent with that expected for a shear-driven wall layer. This is in contrast with many recent studies which suggest higher rates of turbulent kinetic energy dissipation in the near surface of the ocean. However, some dissipation profiles appeared to scale with the sum of the wind and swell generated Stokes shear with this scaling extending beyond the mixed layer depth. Integrating $\epsilon$ in the mixed layer yielded results that $1 \%$ of the wind power referenced to $10 \mathrm{~m}$ is being dissipated here.
\end{abstract}

\section{Introduction}

The level of turbulent kinetic energy in the ocean depends on the balance between energy production, suppression by buoyancy and dissipation. The latter term is representative of the availability of mixing, which is parameterized in largescale numerical models that lack the resolution to directly compute dissipation. There has been considerable effort to understand the scaling of the turbulent dissipation rate of kinetic energy $(\epsilon)$ in the oceanic boundary layer (OBL). Here, $\epsilon$ directly influences many air-sea processes such as the mixing of near-surface water properties (Garrett, 1996; Stevens et al., 2011), gas transfer across the ocean interface (Lorke and Peeters, 2006; Zappa et al., 2007) and the dynamics and evolution of plankton blooms (Denman and Gargett, 1989; Yamazaki et al., 1991). Parameterizing $\epsilon$ in the OBL has proven to be more difficult than in the atmo- spheric boundary layer (ABL) due to the presence of surface gravity waves (Agrawal et al., 1992; Terray et al., 1996) and Langmuir circulations (McWilliams et al., 1997; Grant and Belcher, 2009) creating enhanced dissipation relative to what is expected from a shear driven boundary layer.

There has been a desire for more observations of near-surface values of $\epsilon$ due to the growing prevalence of using large eddy simulations (LES) to model the OBL (McWilliams et al., 1997; Noh et al., 2004; Grant and Belcher, 2009). The key parameter in balancing the sub-grid dynamics is $\epsilon$ and due to it not being resolved directly it is required to be parameterized. However, the lack of observations limits the ability to validate proposed parameterizations (see Noh et al., 2004 or Grant and Belcher, 2009).

Attempts at parameterizing $\epsilon$ in the OBL have traditionally begun with similarity scaling, which treats $\epsilon$ in the OBL in as a shear driven wall layer. This method assumes a constant stress with the mean velocity having a logarithmic profile, so that the shear is

$\frac{\partial \bar{U}}{\partial z}=\frac{u_{*}}{\kappa z}$,

where $\bar{U}, z, \kappa$ and $u_{*}$ are the mean velocity, depth, von Kármán constant $(\kappa=0.40)$ and friction velocity, respectively, defined as:

$u_{*}=\sqrt{\tau / \rho}$,

where $\tau$ is the wind stress and $\rho$ is the density of seawater. The wind stress is assumed to be constant across the airsea interface so that $\tau=u_{*}^{2} \rho=u_{* a}^{2} \rho_{a}$, where the $a$ subscript denotes the air friction velocity and density respectively.

For a steady-state solution the turbulent kinetic energy equation can be written as a balance of shear production, 
buoyancy flux, and turbulent dissipation rate, $\epsilon$, (Osborn, 1980)

$0=-\overline{u^{\prime} w^{\prime}} \frac{\partial \bar{U}}{\partial z}+\frac{g}{\rho} \overline{w^{\prime} \rho^{\prime}}-\epsilon$,

where $u^{\prime}$ and $w^{\prime}$ are the turbulent horizontal and vertical velocities, and $g$ is the acceleration due to gravity. Since the wind stress, $\tau$, can be directly calculated from the Reynolds stress as $\tau=\rho \overline{u^{\prime} w^{\prime}}$ it follows from Eq. (5) that

$\overline{u^{\prime} w^{\prime}}=u_{*}^{2}$.

Therefore, ignoring buoyancy, which is often an order of magnitude smaller than the other terms, and substituting Eqs. (1) and (4) into Eq. (3) leads to the familiar "law of the wall" scaling, i.e.

$\epsilon_{\tau}=\frac{u_{*}^{3}}{\kappa z}$.

Early measurements supported the idea of the ocean as a purely shear driven wall layer. Jones and Kenney (1977) found that turbulence velocity fluctuations scaled with $u_{*}$ with a length scale comparable to the depth. Churchill and Csanady (1983), using quasi-Lagrangian drifters and drogues, reported logarithmic mean current profiles in the OBL, consistent with a constant shear layer. Profile measurements in a lake (Dillon et al., 1981) and in the ocean (Oakey and Elliott, 1982; Soloviev et al., 1988) both found $\epsilon$ to scale with Eq. (5).

Observations by Kitaigorodskii et al. (1983) and subsequently by Agrawal et al. (1992), using velocity microstructure measurements at fixed depths, found enhanced dissipation by 1 to 2 orders of magnitude relative to the law of the wall in the upper ocean. This enhancement was attributed to the presence of breaking surface gravity waves directly injecting turbulent kinetic energy into the near-surface region.

Terray et al. (1996) suggested enhanced $\epsilon$ values could be scaled using parameters of the wind-wave field having a vertical structure with three distinct regions. The uppermost region from the surface down to a depth $z_{b}=0.6 H_{\mathrm{s}}$, where $H_{\mathrm{s}}$ is the significant wave height, experiences a large uniform turbulent dissipation rate due to the presence of breaking waves. The dissipation rate in this region is an order of magnitude greater than predicted by Eq. (5). Below this there is an intermediate region of enhanced $\epsilon$ which has decays as $z^{-2}$. This enhanced region extends to $z_{t}=0.3 H_{\mathrm{s}} \kappa \bar{c} / u_{* a}$, where $\bar{c}$ is the effective wave speed equating the energy input from the wind to the waves, $F=\bar{c} u_{*}^{2}$ and $u_{* a}$ is the air side friction velocity. The ratio of $\bar{c} / u_{* a}$ is related to the wave age $c_{w} / u_{* a}$, where $c_{w}$ is the phase velocity of the wind generated waves. Hence, it was the conclusion of Terray et al. (1996) that the depth of the enhanced region is dependent on the wave age as well as the significant wave height. Below this depth $\epsilon$ scales as Eq. (5). The same depth dependence of $\epsilon$ was found by Drennan et al. (1996) using fixed depth velocity measurements from the bow of a ship in a mixed swell/wind sea in the Atlantic. Further support for enhanced dissipation has been established by several ocean studies, but with various depth profiles for $\epsilon$ (Gargett, 1989; Anis and Moum, 1995; Greenan et al., 2001). In a study in the North Pacific using a microstructure profiler Gargett (1989) found $\epsilon \propto z^{-4}$ in the mixed layer during a week of intermittent stormy weather, which relaxed to $\epsilon \propto z^{-1}$ as the wind and sea states calmed.

Anis and Moum (1995), using a rising vertical profiler in the Pacific Ocean, reported enhanced dissipation with respect to Eq. (5) with an exponential depth decay. A profile of $e^{2 k z}$, where $k$ is the dominant wave number of the surface wave field, matched closely with the observed wave number associated with the wind generated waves during enhanced dissipation. This $e^{2 k z}$ depth dependence was explained theoretically by a rotational wave field with only a small deviation from quadrature necessary, on the order of a couple of degrees, to re-create their observed dissipation levels. This $e^{2 k z}$ depth dependence of turbulent kinetic energy dissipation was also found by Huang and Qiao (2010) by ignoring the buoyancy term in Eq. (3), i.e.

$\epsilon_{w}=a_{1} u_{*}^{2} \frac{\partial u_{s}}{\partial z}$,

where $u_{s}$ is the stokes drift induced by surface waves. For a monochromatic wave the Stokes drift is

$u_{s}=u_{s 0} e^{2 k z}$,

where the magnitude at the surface is equal to $u_{s 0}=c(a k)^{2}$ and $c, a$ and $k$ are the wave speed, amplitude, and wave number, respectively. In Eq. (6), $a_{1}$ is a dimensionless constant associated with the surface waves and predicted by regression. Using the observations of Anis and Moum (1995), Huang and Qiao (2010) estimated $a_{1}$ to be

$a_{1}=3.75 \beta \pi \sqrt{\frac{H_{\mathrm{s}}}{\lambda}}$,

where $\lambda$ is the dominant wavelength and $\beta$ is a dimensionless constant between 0 and 1. Huang and Qiao (2010) compared Eq. (6) with observations by Anis and Moum (1995), Osborn et al. (1992) and Wüest et al. (2000) with an order of magnitude agreement for values of $\beta$ between 0.15 and 1 .

Studies are ongoing in this field (Stevens and Smith, 2004; Gerbi et al., 2009) and it is still unclear on the role surface waves play in dissipation (Babanin and Haus, 2009; Huang and Qiao, 2010; Teixeira, 2012). Observations of $\epsilon$ in the deep ocean (Greenan et al., 2001) suggest that any scaling may not be straight forward especially in the presence of complex wave fields.

Over recent years there has been a large increase in modelling the OBL using large eddy simulations (LES). LES models have shown to be very effective in the ABL, while 


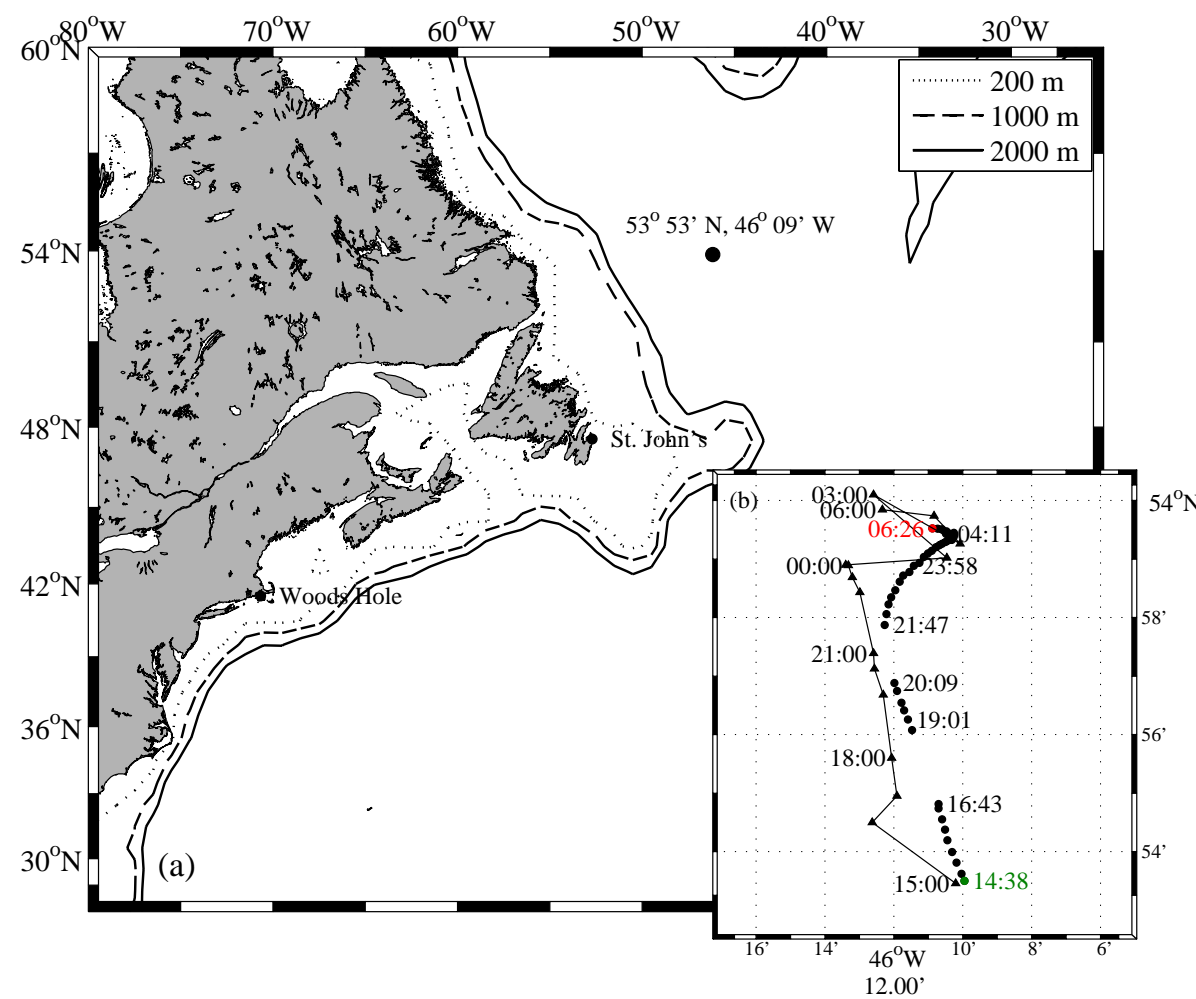

Fig. 1. (a) The $200 \mathrm{~m}, 1000 \mathrm{~m}$, and $2000 \mathrm{~m}$ depth contours are shown for the North Atlantic with the deployment location shown by the large black dot. Inset map (b) shows the ASIP profile locations (black dots) with the green dot being the first profile and the red dot showing the final profile. The ship locations at three hour intervals are shown by the black triangles. All times are in local mean time.

attempts in the OBL have been hindered by the difficulty of handling the boundary condition at the surface. The difficulty lies in the lack of observations of $\epsilon$ in the near surface and that without these measurements it is difficult to properly model these processes accurately (Noh et al., 2004; Grant and Belcher, 2009).

In this paper we describe a set of observations taken during a research cruise in the North Atlantic with the upwardly rising Air-Sea Interaction Profiler (ASIP) microstructure instrument, an ultrasonic wave altimeter, and a high quality suite of meteorological sensors. Details of all the available measurements and processing algorithms are presented in Sect. 2. Dissipation scaling in the upper ocean, including wave-induced scaling and comparisons of the integrated dissipation with the wind input, is discussed in Sect. 3. A summary of the results are presented in Sect. 4.

\section{Measurements}

Measurements were conducted during a field campaign in the North Atlantic (Fig. 1a) aboard the R/V Knorr from late June to mid-July 2011. Presented here is one deployment of the Air-Sea Interaction Profiler (ASIP), an autonomous microstructure profiler designed to study the OBL (Ward and Fristedt, 2008). A total of 54 profiles were made spanning 16h from 2 July 2011 14:38 to 3 July 2011 06:26 LMT. The drift track of ASIP and the ship position over the course of the deployment can be seen in Fig. 1b. The location is determined via the GPS receiver on ASIP which obtains a position at the surface after each profile. There are two gaps in the profiling, from 16:43 to 19:01 LMT and 20:09 to 21:47 LMT, where ASIP was unable to obtain a valid GPS location and profiling was temporarily suspended. All times are in local mean time (LMT), which aligns noon with the maximum solar angle. For the measurement location (Fig. 1b) this corresponds to a time difference of $3 \mathrm{~h}$ and $8 \mathrm{~min}$ behind UTC.

\subsection{Microstructure measurements}

ASIP is equipped with two FP07 micro-scale temperature sensors, one SBE 7 micro-conductivity sensor, and two SPM38 vertical shear microstructure sensors from which $\epsilon$ was computed (Macoun and Lueck, 2004). In addition to these, there is an accurate (CTD-standard) temperature and conductivity sensor manufactured by Neil Brown Ocean Sensors Inc. (NBOSI), a Licor LI-92 Photosynthetic Active Radiation (PAR) sensor which measures incoming short-wave radiation (between 400 and $700 \mathrm{~nm}$ ), a Keller pressure sensor, and accelerometers and orientation sensors. ASIP is positively buoyant rising upwards with a nominal speed of $0.5 \mathrm{~m} \mathrm{~s}^{-1}$. In the wave affected region in the upper ocean, the rise velocity 
is calculated from a linear fit of the pressure record for the upper $10 \mathrm{~m}$. A linear fit of the pressure gradient ensures that the effects of waves are filtered out of the pressure signal. This is identical to the method adopted by Stips et al. (2005) to calculate rise velocities of a rising vertical profiler in the presence of surface waves.

The location of the ocean surface is determined for each profile from the micro-conductivity record, using a surface detection method similar to Stips et al. (2005). The uncertainty in the surface location is estimated to be $\pm 2 \mathrm{~cm}$, determined from examining hundreds of profiles in various sea states, and this result is consistent with Stips et al. (2005). The other sensors are aligned to the micro-conductivity sensor so each measurement is referenced to the same depth. Details of the surface detection and calibration algorithms can be found in ?.

Turbulence parameters are calculated from the measured vertical shear (Osborn, 1974; Moum et al., 1995) over segments of 1024 points with a 512 point overlap. The vertical resolution depends on the sampling rate and rise velocity and in our case the resolution was approximately $0.5 \mathrm{~m}$. Various segment lengths were tested and the 1024 segment length was found to provide a good balance between statistical significance and homogeneity. A sample spectrum taken from a profile at 2 July 2011 17:15 LMT during moderate wind speeds can be seen in Fig. 2. To ascertain the presence of any persistent noise artifacts, a spectrogram is calculated (Fig. 3e) from the raw shear signal (Fig. 3c) for each profile. There is a faint signal at $30 \mathrm{~Hz}$, which corresponds to a wave number of $\approx 60 \mathrm{cpm}$, but this is only prominent where the signal is low and the calculated $\epsilon$ is below the adopted noise floor of $5 \times 10^{-10} \mathrm{~m}^{2} \mathrm{~s}^{-3}$ (Fig. 3d).

\subsection{Meteorological measurements}

Meteorological data represent the direct forcing to the OBL. This includes wind forcing and buoyancy forcing. The buoyancy forcing is represented as the change in density at the surface from radiative forces changing the temperature and hydrological forces, such as rain and evaporation, altering the salinity. These data were recorded continuously throughout the campaign with the on-board data acquisition system on the R/V Knorr. Measurements were recorded at one minute intervals and these were averaged into $30 \mathrm{~min}$ bins.

Wind measurements were recorded using two Vaisala WXT520 weather sensors mounted at $15.5 \mathrm{~m}$ above the waterline on the forward mast on both port and starboard sides respectively. Measurements are sampled at $2 \mathrm{~Hz}$ and these are averaged and recorded at one minute intervals. The wind measurements at $15.5 \mathrm{~m}$ are corrected to the standard $10 \mathrm{~m}$ above sea level using the TOGA COARE 3.0 algorithm which assumes a logarithmic profile with height (Fairall et al., 1996, 2003).

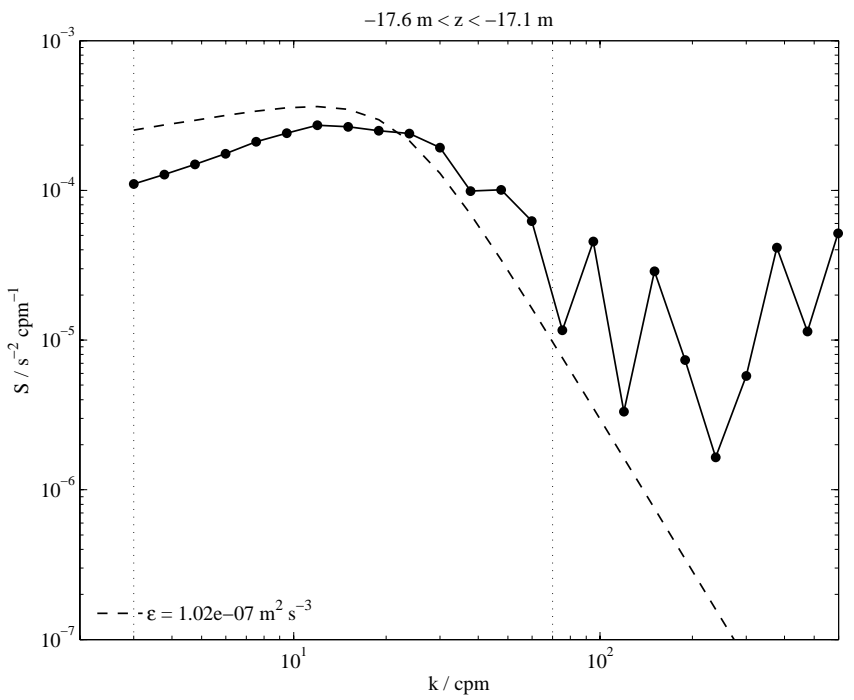

Fig. 2. Sample shear spectrum (black dots) and modelled Nasmyth spectrum (dashed line) for the depth interval $-17.6 \mathrm{~m}<z<$ $-17.1 \mathrm{~m}$ of the profile corresponding to Fig. 3. The lower and upper integration limits are denoted by the vertical dashed lines.
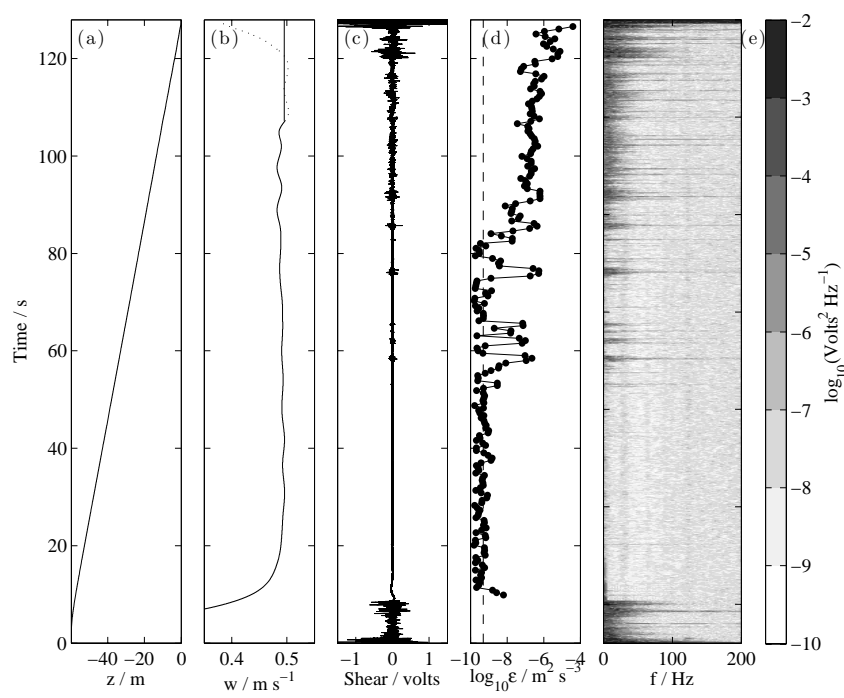

Fig. 3. Spectrogram of a profile taken at 17:15 LMT (e). The depth and corresponding rise velocity are shown in (a) and (b). A uniform rise speed is adopted in the upper $10 \mathrm{~m}$ (solid line) to filter out wave effects in the pressure signal (dotted line). (c) shows the raw shear signal in volts and the calculated dissipation rate is in (d).

The density flux $\left(Q_{p}\right)$ into the ocean from the atmosphere was computed as (e.g. Zhang and Talley, 1998)

$Q_{p}=\rho\left(\alpha F_{T}+\beta F_{S}\right)$,

where $\alpha$ and $\beta$ are the thermal expansion and saline contraction coefficients, respectively. Here $F_{T}=-Q_{\text {net }} / \rho_{s} C_{p}$ and $F_{S}=(E-P) S /(1-S / 1000)$, where $C_{p}$ is the specific heat 
of sea water and $E, P$ and $S$ are the evaporation, precipitation and sea surface salinity, respectively.

The net radiative heat flux at the ocean surface is calculated from the combination of the incoming short wave (SW), net incoming and emitted long wave (IR), sensible heat (SH) and latent heat (LE), i.e.

$Q_{\text {net }}=\mathrm{SW}+\mathrm{IR}+\mathrm{SH}+\mathrm{LE}$.

Short-wave and long wave components were measured from the deck of the R/V Knorr (S. Miller, personal communication, 2012) while both SH and LE were computed using TOGA COARE 3.0 flux algorithm (Fairall et al., 1996, 2003).

The buoyancy flux, $B$, is a function of the density flux at the surface, i.e.

$B=\frac{-g Q_{p}}{\rho_{0}}$,

where $g$ is the acceleration due to gravity and $\rho_{0}$ is the reference density for the buoyancy flux. The minus sign indicates that the upper surface becomes less buoyant (i.e. more dense) when there is a positive buoyancy flux out (i.e. upwards) of the ocean surface. $B>0$ implies the density flux is negative (i.e. into the ocean) and is destabilizing which may lead to convection. If $B<0$ then the mass flux is out of the sea, leading to stabilizing conditions.

\subsection{Mixed layer depth}

The mixed layer depth represents the depth at which the surface properties such as temperature and salinity are deemed homogeneous. However, the mixed layer is a dynamic region and there are many different methods for calculating the depth of this layer (see Thomson and Fine, 2003; de Boyer Montégut et al., 2004; Stevens et al., 2011 for a brief literature review of some of the methods used historically). In determining the mixed layer depth, $D$, we use the same threshold value as de Boyer Montégut et al. (2004) of a $0.03 \mathrm{~kg} \mathrm{~m}^{-3}$ increase in the potential density from a reference depth. To avoid effects of diurnal heating in their selection criterion, de Boyer Montégut et al. (2004) use a reference depth of $10 \mathrm{~m}$. For our measurements we found $5 \mathrm{~m}$ was an adequate reference depth to avoid diurnal influences.

An important term in determining stability in the water column is the Monin-Obukhov length scale, defined as

$L=-\frac{u_{*}^{3}}{\kappa B}$.

Equation (12) is a measure of the relative importance of wind forcing to buoyancy forcing and is negative for destabilizing conditions and and positive for stabilizing conditions. The Monin-Obukhov length is often compared with the mixed layer depth $D$ as a bulk stability parameter in similarity scaling. Small values for the ratio $|D / L|$ indicate stability with increasing values of $-D / L$ leading towards greater instability and eventually overturning.

\subsection{Wave measurements}

Surface gravity waves directly force the OBL and are comprised a combination of non-locally generated swell and local wind waves. The wave measurements were made using an ultrasonic altimeter mounted at the bow. The altimeter was combined with an accelerometer to correct for ship motion and a time series of the sea surface elevation was obtained. This time series was then bandpass filtered $(0.05-0.5 \mathrm{~Hz})$ and consecutive half hour periods were used to calculate one dimensional surface wave spectra. For each $30 \mathrm{~min}$ spectra the significant wave height $H_{\mathrm{S}}$ and the zero-upcrossing period $T_{0}$ can be approximated from the $n$-th spectral moment, defined as

$m_{n}=\int_{0}^{\infty} f^{n} S(f) \mathrm{d} f$,

where $S(f)$ and $f$ are the variance spectrum and frequency, respectively. Using Eq. (13) we can write $H_{\mathrm{S}}$ and $\mathrm{T}_{0}$ as

$H_{\mathrm{S}} \approx 4 \sqrt{m_{0}}$

and

$\mathrm{T}_{0} \approx \sqrt{m_{0} / m_{2}}$,

respectively (Bouws et al., 1998). Data collected while the ship was cruising were discarded. The method has been tested successfully in previous field tests, yielding good agreement with data from a waverider buoy (Christensen et al., 2012).

In the absence of independent wave measurements we have compared our data with the ERA-Interim reanalysis of ECMWF (Dee et al., 2011). Values of significant wave height and zero-upcrossing period agree well (see Fig. 4). The wave model data are six hour averages over a spatial range of approximately $120 \mathrm{~km}^{2}$ (i.e. $0.1^{\circ}$ resolution) and our measurements contain significantly more variability. Our measured values are typically within $\pm 10 \%$ of the wave model data for the entire cruise period.

We consider here that the significant wave height $\mathrm{H}_{\mathrm{S}}$ varied between 1.8 and $2.8 \mathrm{~m}$ (Fig. $4 \mathrm{a}$ ), and the zeroupcrossing period $T_{0}$ varied between 4.5 and $6.5 \mathrm{~s}$ (Fig. 4b). On 2 July 2011 22:00 local time, the sea state was dominated by short swell with a peak period of $9.0 \mathrm{~s}$. As the wind increased the sea state was later on dominated by wind waves; at 3 July 2011 01:00, the peak period had dropped to $5.8 \mathrm{~s}$, but with a second peak at $8.6 \mathrm{~s}$. Towards the end of the period we found mixed seas and a wide spectrum with a peak period of $7.7 \mathrm{~s}$ (see Fig. 5).

\subsection{Upper ocean parameters}

During this deployment an intense low pressure system passed over the R/V Knorr as can be seen in the drop and 


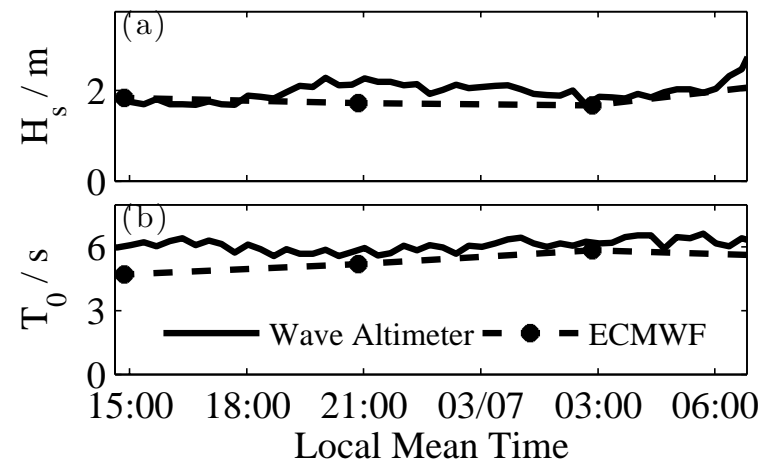

Fig. 4. Comparison of (a) significant wave height and (b) zeroupcrossing period for data collected with the ultrasonic wave altimeter (solid line) and the ERA-Interim reanalysis of ECMWF (dots connected by dashed line). Time is in local mean time.

subsequent rise in atmospheric pressure (Fig. 6a). The leading edge of the low pressure system (Fig. 6a) was accompanied by moderate to heavy rainfall (Fig. 6c) and a uniform wind velocity of $11 \mathrm{~m} \mathrm{~s}^{-1}$ (Fig. 6b). The wind speed rapidly decreased to $<4 \mathrm{~m} \mathrm{~s}^{-1}$ at 2 July 21:00 LMT, accompanied by a $2{ }^{\circ} \mathrm{C}$ drop in air temperature (Fig. 6c) until at 3 July 04:00 LMT where the wind speed increased to $>17 \mathrm{~m} \mathrm{~s}^{-1}$. The wave field changed little during the deployment with the zero-upcrossing time slightly increasing as the wind forcing decreased (Fig. 6d).

The net radiation (Fig. 7a) and buoyancy fluxes (Fig. 7b) show a net loss of heat and mass from the ocean to the atmosphere during the course of the deployment. The one exception to this was the salt component of the buoyancy flux (Fig. 7b) due to a large rain event on the leading edge of the storm.

Although the buoyancy forcing was unstable for the majority of the deployment (Fig. 7b), the ratio of the MoninObukhov length to the mixed layer depth was greater than unity (i.e. $|-L| / D \gg 1$ ), which implied that the wind forcing was significantly greater than the destabilizing buoyancy forcing. Only during the lull in the wind from 2 July 21:00 to 3 July 05:00 LMT does the ratio of $-L / D<1$, indicative of a convective overturning regime.

The temperature (Fig. 8a) and salinity (Fig. 8b) from ASIP indicates that the deployment began with relatively warm and fresh water with the latter due to the rain at the beginning of the deployment (Fig. 6c). Overnight the upper $20 \mathrm{~m}$ were relatively homogeneous with little variation in the mixed layer depth. At 05:00 the wind rapidly increased (Fig. 6b) which resulted in an increase of the mixed layer depth from $15 \mathrm{~m}$ to $40 \mathrm{~m}$ in about $0.5 \mathrm{~h}$.

The response of the upper mixed layer to atmospheric buoyancy and wind stress (Fig. 9b) can be seen in the evolution of $\epsilon$ (Fig. 9d). In the mixed layer, the regions of high turbulent dissipation follow very closely with the mixed layer depth except during the evening when the wind is calm. The

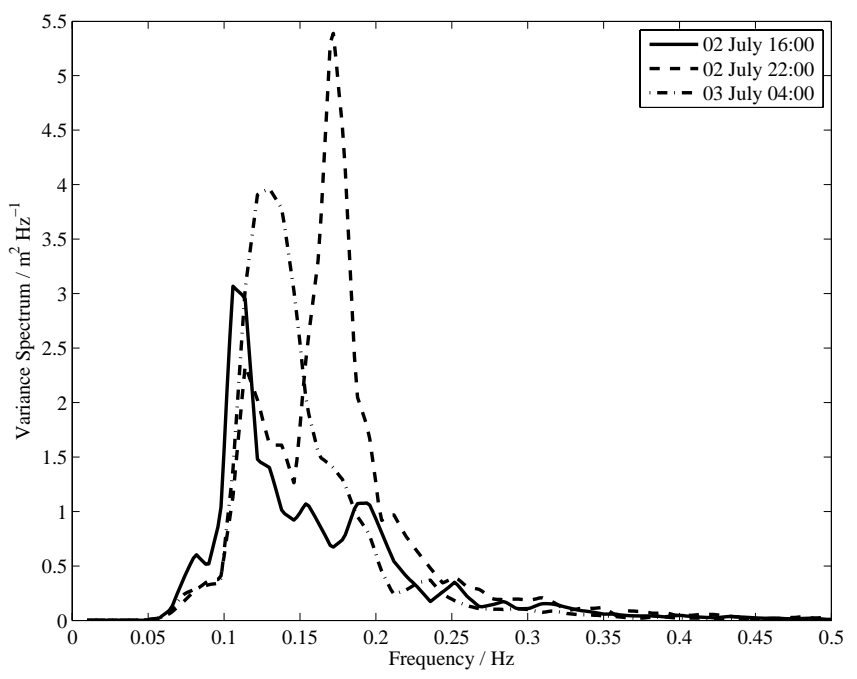

Fig. 5. Time evolution of wave spectra over six-hour time intervals.

most likely cause of the discrepancy was due to inadequacies of using a single mixed layer depth parameterization to encompass all the various forcing conditions encountered. The stratification in the mixed layer was complex (Fig. 9c) and often there were small gradients in the upper few meters which were strong enough to inhibit turbulence under mild forcing. Also, the use of a reference depth of $5 \mathrm{~m}$ limits values for the mixed layer depth to be $D \geq 5 \mathrm{~m}$.

The turbulent Langmuir number, defined as $L a_{t}=\sqrt{u_{*} / u_{s} 0}$, is shown in Fig. 9a. $L a_{t}$ is used as an indicator for when Langmuir circulation begins to be the dominant mechanism for shear driven turbulence in the OBL. Values of $L a_{t}<0.3$ generally correspond with Langmuir dominated turbulence Grant and Belcher (2009). The wave field does not vary much over the deployment (see Fig. 6d) thus $L a_{t}$ closely follows the wind stress in Fig. 9. During the evening $L a_{t}$ drops from about 0.4 to 0.2 indicating that Langmuir generated turbulence to be dominating. However, during this period (from around 2 July 22:00 to 3 July 2011 04:30 LMT) most of the turbulence is restricted to the upper $10 \mathrm{~m}$ (see Fig. 9d) and it is not clear if there is any enhancement in this region.

\section{Discussion}

We begin our analysis in Sect. 3.1 with a look at the overall energy budget in Sect. 3.1 by comparing the vertically integrated dissipation rate with the energy input from the wind. This is followed by our discussion of the profile shapes of $\epsilon$ by comparing these profiles with that expected from the law of the wall (Sect. 3.2) and from a wave-induced shear (Sect. 3.3). 


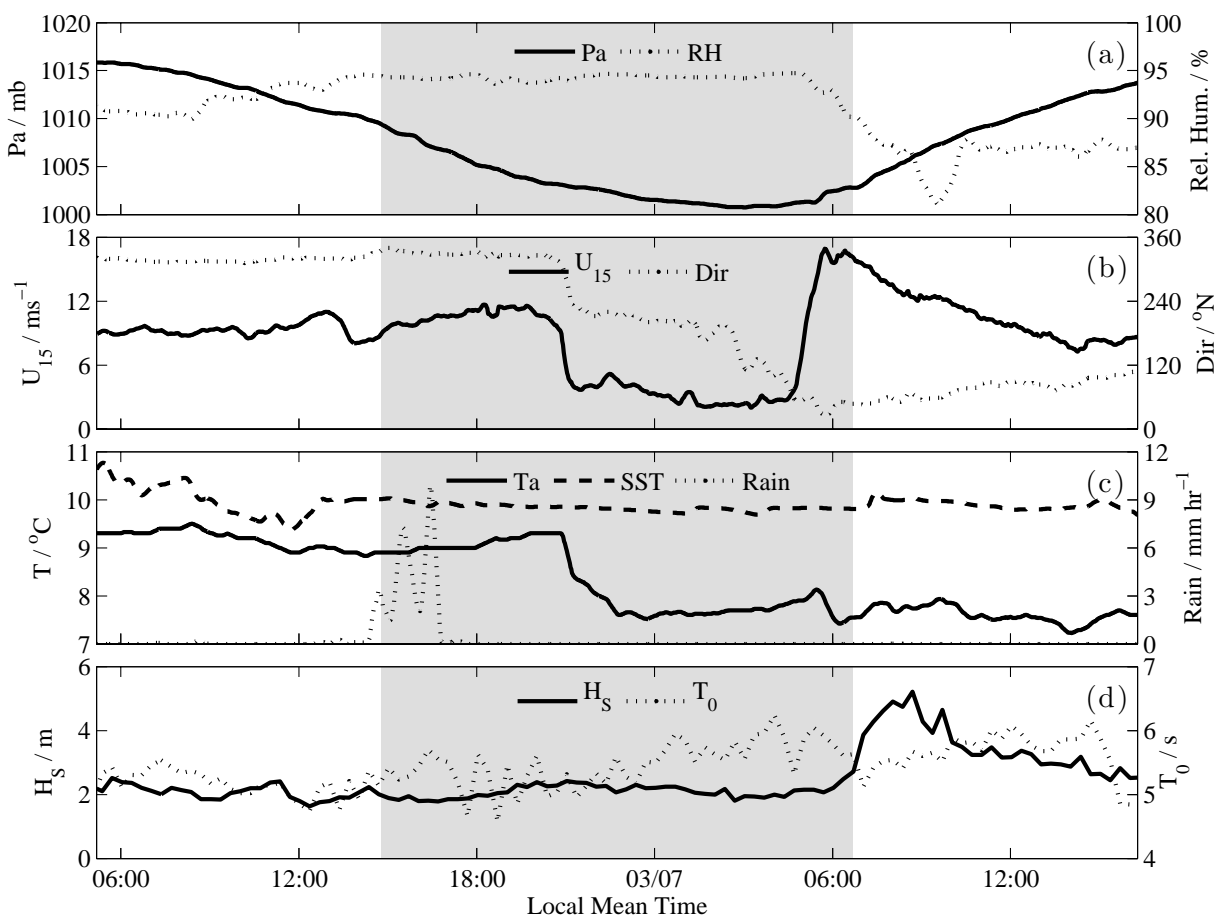

Fig. 6. (a) Pressure $(\mathrm{Pa})$, relative humidity $(\mathrm{RH})$, (b) wind speed at $15.5 \mathrm{~m}\left(U_{15}\right)$, wind direction (Dir, clockwise from north), (c) air temperature (Ta), sea surface temperature (SST), rainfall rate (Rain), (d) significant wave height and mean crossing period are shipboard measurements from the R/V Knorr for the deployment location in Fig. 1. The shaded region corresponds to the time when ASIP was profiling.
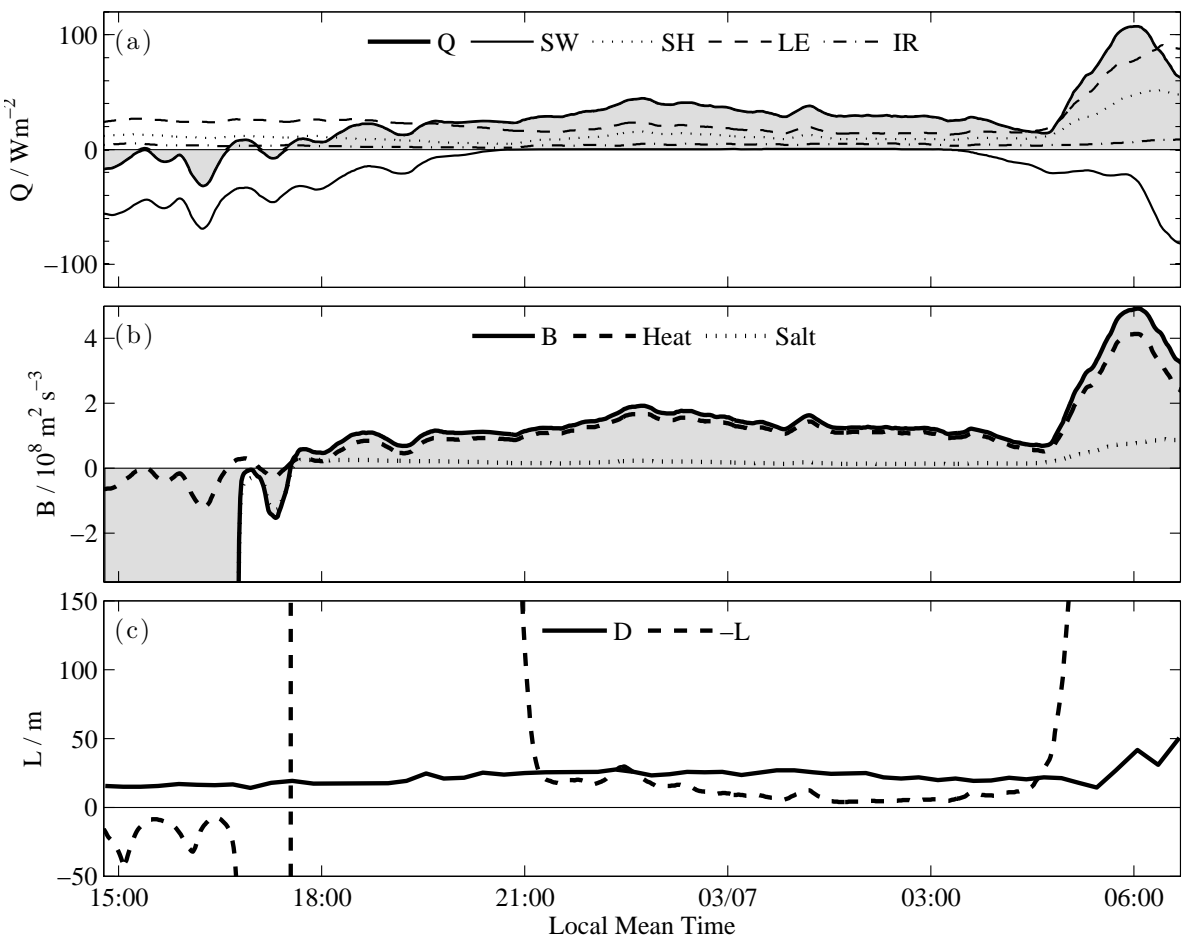

Fig. 7. (a) Net radiative flux ( $Q$ ), short wave (SW), sensible heat (SH), latent heat (LE), and net infrared (IR) radiation during the deployment. Positive is upwards out of the ocean. The net surface buoyancy flux $(B)$ and the relative contributions from heat and salt and shown in (b). (c) shows the mixed layer depth $(D)$ and the Monin-Obukhov length $(L)$. 


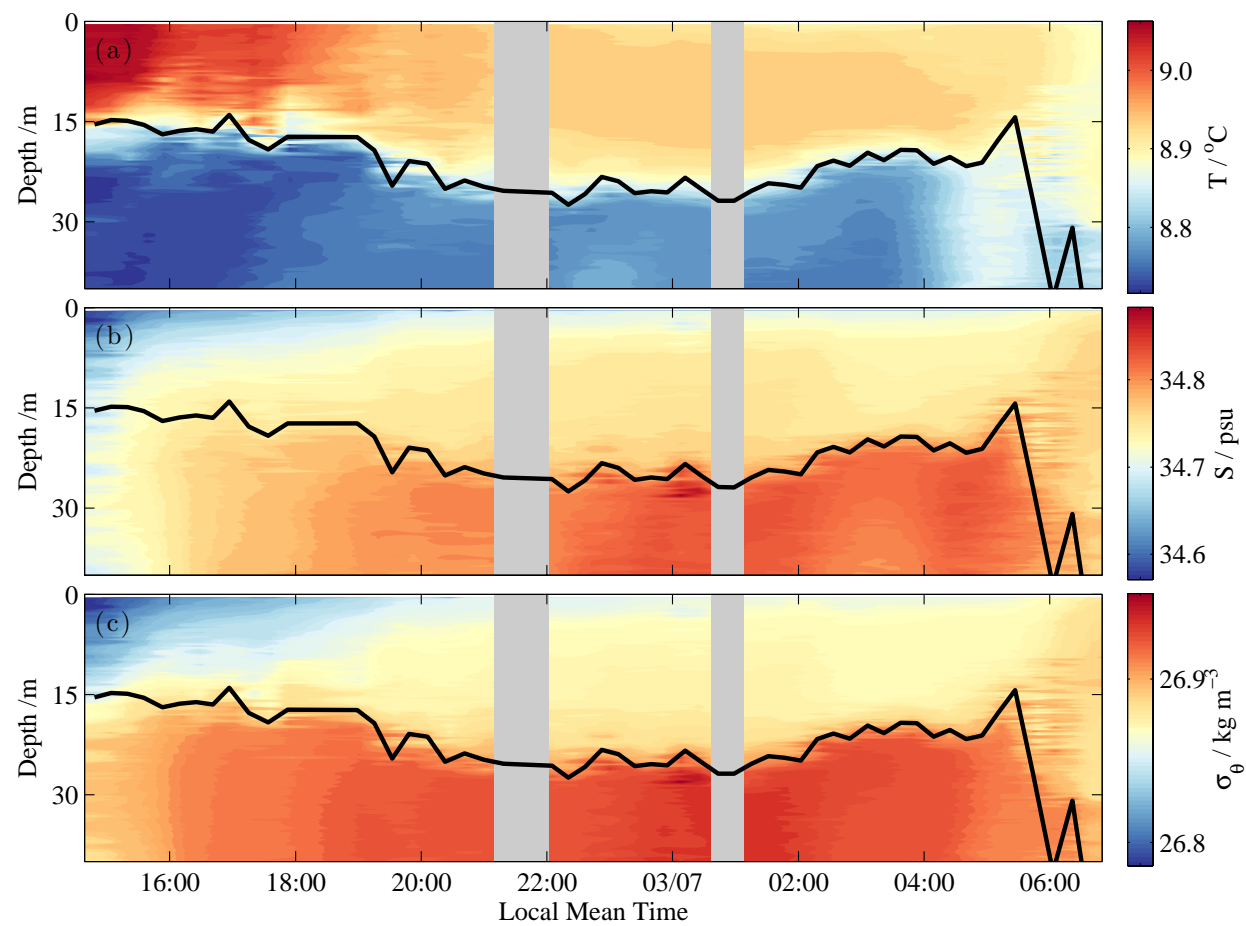

Fig. 8. (a) Temperature, (b) salinity, and (c) potential density as measured by the ASIP profiler. The solid black line denotes the mixed layer depth and the time has been corrected to local mean time.

\subsection{Integrated energy flux}

It is often convenient to discuss dissipation in terms of the total dissipation rate in the mixed layer. This is defined as the vertically integrated dissipation rate, i.e.

$\epsilon_{I}=\int_{-D}^{0} \rho \epsilon \mathrm{d} z$

where the units of $\epsilon_{I}$ are in $\mathrm{Wm}^{-2}$. Equation (16) can be conveniently used to compare the total energy input from the surface wind field. The input wind power may be estimated from the wind speed reference to $10 \mathrm{~m}$ height, i.e.

$E_{10}=\tau U_{10}$,

where $\tau$ is the wind stress and $U_{10}$ is the wind speed referenced to $10 \mathrm{~m}$. Comparing Eq. (17) with Eq. (16) can demonstrate what percentage of the wind power was going into mixing the OBL. Most of the energy flux in the lower atmosphere is dissipated in the air before it ever reaches the surface so this ratio is expected to be small. Using a combination of field and laboratory results, Richman and Garrett (1977) estimated that 4-9\% of $E_{10}$ would be dissipated in the mixed layer. Later direct measurements of $\epsilon$ by Oakey and Elliott (1982) found $\epsilon_{I}$ to be $1 \%$ of $E_{10}$. Computing Eq. (16) for this deployment found excellent agreement with the $1 \%$ value of Oakey and Elliott (1982) with the results shown in
Fig. 11. The one discrepancy is during the night where a combination of an overestimation of the mixed layer depth and buoyancy-induced turbulent dissipation create a slightly greater integrated dissipation level relative to $1 \%$ of the wind power.

This result that $1 \%$ of the wind power is dissipated in the mixed layer is similar to previous observations by Stewart and Grant (1962); Dillon et al. (1981) and a shear-driven wall layer where $\epsilon$ follows Eq. (5). However, there are many cases (Kitaigorodskii et al., 1983; Greenan et al., 2001) where this ratio is closer to the $4-9 \%$ predicted by Richman and Garrett (1977) suggesting a greater input of energy into mixing the upper ocean. Anis and Moum (1995) generally found the total dissipation of turbulent kinetic energy to be consistent with Oakey and Elliott (1982), but found a few occasions where integrated dissipation was much closer to $10 \%$ suggesting that this may not be a constant value.

\subsection{Dissipation rate scaling - law of the wall}

The measured turbulent dissipation rate from ASIP was compared to the estimates from Eq. (5), with this ratio shown in Fig. 9e. For the majority of the deployment $\epsilon$ scales within an order of magnitude with Eq. (5) in the mixed layer. The exception to this was during the night where $\epsilon$ was larger than expected from Eq. (5) between 2 and $15 \mathrm{~m}$. As the night progressed, starting at 3 July 2012 03:00 LMT, there was a region of enhanced $\epsilon$ in the near-surface water that was slowly 


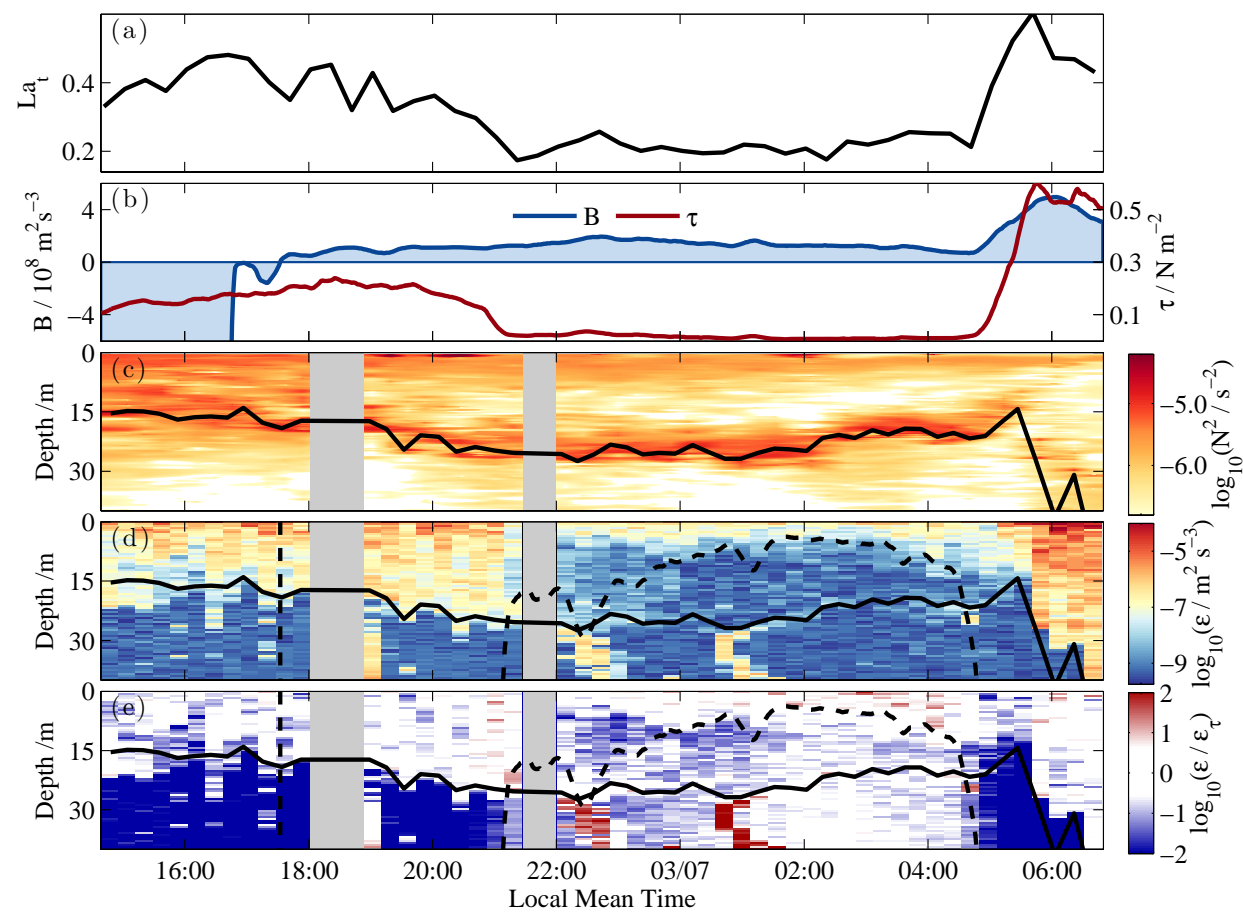

Fig. 9. (a) Turbulent Langmuir number, (b) buoyancy and wind stress forcing, (c) Brunt-Väisäla frequency $N^{2}$, (d) dissipation $\epsilon$ and dissipation normalised by the law of the wall (Eq. 5) (d). The solid black line in (c-e) denote the mixed layer depth $D$ and the dashed line in (d) and (e) is the Monin-Obukhov length $L$. All times have been converted to local mean time.

extending deeper into the mixed layer depth. This time corresponded with a region of small $-L$ (Fig. 6c) as well as $L a_{t}<0.3$, which indicates that conditions were favourable for turbulence enhancement from convective overturning as well as Langmuir circulation.

\subsection{Wave induced turbulence}

Profiles of $\epsilon$ were also modelled using Eq. (6) as proposed by Huang and Qiao (2010), who investigated profiles of turbulent dissipation induced by shear created by Stokes drift. This leads to a depth dependence of $\epsilon \propto e^{2 k z}$, where $k$ is the wave number of the wave field. Figure 10a-c show the wave scaling for dissipation profiles averaged over one hour in time (i.e. 5 successive profiles) and one meter in depth. The grey shaded region represents the $95 \%$ confidence intervals for each bin using the bootstrap method (Efron and Gong, 1983). To determine $k$, the wave spectra (Fig. 10d-f) was divided into two sections (labelled I and II), where $k$ was calculated for each section from the mean spectral period and the dispersion relation for deep water gravity waves, i.e. $\omega^{2}=g k$ where $\omega$ is the angular frequency. The significant wave height was also calculated separately for each spectral bin. A value for $\beta$ of 0.15 was adopted for all subsequent estimates using Eq. (6), consistent with the findings of Huang and Qiao (2010).

Several profiles of $\epsilon$ (Fig. 10a-c) are compared with observations including Eq. (5), Terray et al. (1996), and the wave scaling of Huang and Qiao (2010). For the scaling of Terray et al. (1996) II is used to determine the wave age and hence the depth of the transitional layer, $z_{t}$. Any errors associated with this choice for the wave age will only affect the depth of the transitional layer and will not affect the depth dependence of $\epsilon$. Early in the deployment profiles were taken in steady wind forcing and developed seas $\left(c_{w} / u_{* a} \approx 80\right)$. In this case $\epsilon(z)$ follows an exponential depth dependence (Fig. 10a, solid red line) even below the mixed layer depth suggesting that shear generated by the Stokes drift of swell with long wavelengths may be a mechanism for mixing below the mixed layer depth.

The profile of $\epsilon$ during the night when the wind dropped to below $5 \mathrm{~m} \mathrm{~s}^{-1}$ is shown in Fig. 10b. The wave age is still $\approx 80$ but the direct wind forcing has died down and the buoyancy forcing, which is on the order of $10^{-8} \mathrm{~m}^{2} \mathrm{~s}^{-3}$, is now comparable to measured dissipation rates in the mixed layer. Between 5 and $18 \mathrm{~m}$ the slope of $\epsilon$ follows the wave induced dissipation profiles accurately, but above this $\epsilon$ decays more closely to that predicted by Terray et al. (1996). This is likely a result of the low dissipation levels encountered during the night.

When the wind increased at the end of the deployment, the dissipation profile became less continuous with more discrete jumps in $\epsilon$, as shown in Fig. 10c. While the wave field was developing (wave age $\approx 10$ ), the high winds appeared to reveal a more incremental approach to a rapidly decreasing 

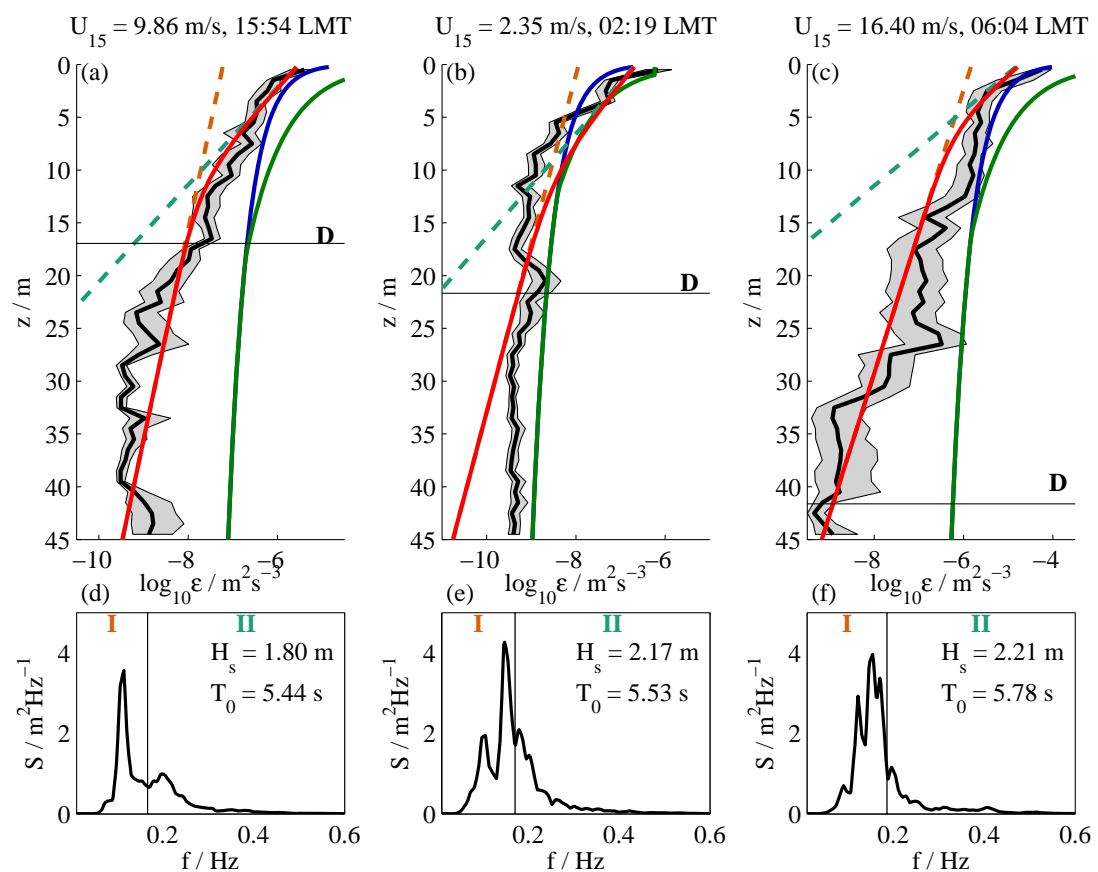

Fig. 10. Profiles of turbulent kinetic energy dissipation (a-c) for a particular wave spectra (d-f). Five successive profiles of $\epsilon$ taken over one hour are averaged vertically into $1 \mathrm{~m}$ bins with the solid black line showing the mean and the grey shaded region the $95 \%$ confidence intervals determined using a bootstrap method. The depth dependence of $\epsilon$ is compared with Eq. (5) (blue line), scaling of Terray et al. (1996) (green line), and the wave scaling of Huang and Qiao (2010) (red line) using portions of the wave spectra along with Eq. (6) (dashed lines with colours matching the corresponding spectral region marked by I, and II in $\mathbf{d}-\mathbf{f}$ ). The red line denotes the sum of the wave scaling turbulence profiles from section I and II, i.e. the dashed orange line plus the dashed green line. The values of $H_{\mathrm{S}}$ and $T_{0}$ for each wave spectra are computed for the entire spectra. The mixed layer depth is the black horizontal line denoted by $D$.

mixed layer, as is seen in the order of magnitude drops in $\epsilon$ at $\approx 15 \mathrm{~m}, \approx 27 \mathrm{~m}$ and $\approx 32 \mathrm{~m}$ (Fig. 10c). The dissipation rate between $2 \mathrm{~m}$ and the remnant mixed layer depth of $15 \mathrm{~m}$ had a near-uniform dissipation rate with little variability as denoted by the confidence intervals. There were subsequent drops in $\epsilon$ at $27 \mathrm{~m}$ and $32 \mathrm{~m}$ with near-uniform values of $\epsilon$ in between suggestive of incremental steps in eroding the mixed layer. None of the dissipation models do particularly well in this scenario with an increasing wind with Eq. (5) appearing to be the best in the upper $10 \mathrm{~m}$ and Huang and Qiao (2010) faring better below.

\section{Summary}

Measurements of the dissipation rate of turbulent kinetic energy along with measurements of atmospheric fluxes and wave spectra are presented in detail for a field campaign in the North Atlantic during July 2012. Accurate observations of all of these parameters simultaneously in the open ocean are extremely rare, especially in the presence of mixed seas where it is difficult to distinguish between the swell and wind generated waves. Dissipation measurements were made with the Air-Sea Interaction Profiler (ASIP), which is an unique instrument designed for profiling the mixed layer

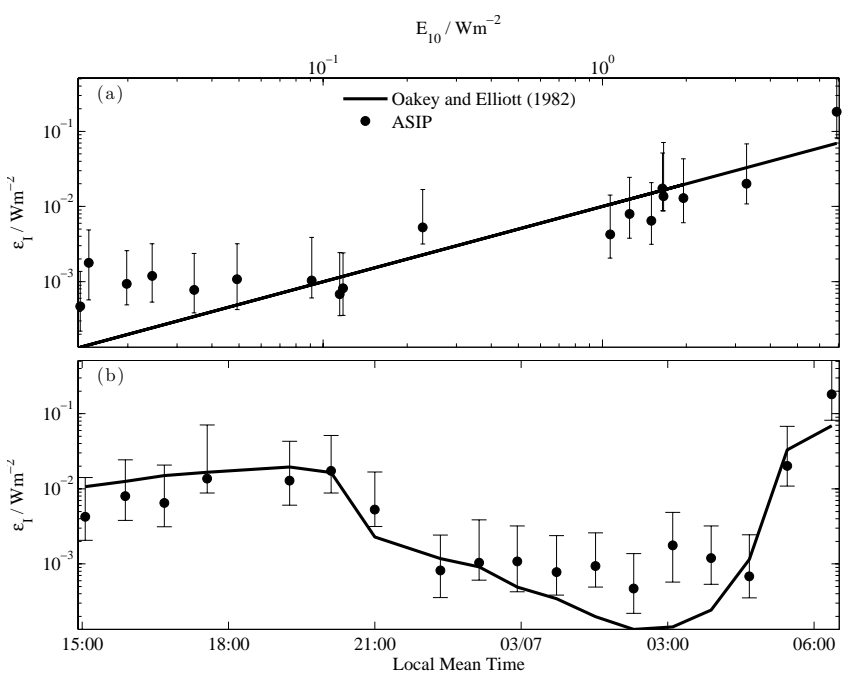

Fig. 11. Depth integrated dissipation rate in the OBL as a function of wind speed at $10 \mathrm{~m}$. (a) shows the integrated dissipation as a function of input wind energy while (b) shows this quantity as a function of local time. The individual profiles are averaged into $1 \mathrm{~h}$ by $1 \mathrm{~m}$ bins and the error bars represent the limits of the integrated $95 \%$ confident limits as determined with a bootstrap method. 
of the ocean. ASIP is a vertically rising profiler which functions autonomously allowing the profiler to be sufficiently far away from any ship induced effects to allow for measurements up to the ocean surface. Direct measurements of $\epsilon$ were obtained during the transit of an intense low pressure system allowing for a wide range of sea states to test various scaling laws.

The results were used to test various scaling laws proposed for the depth dependence of $\epsilon$. Specifically, the classic wall layer where $\epsilon \propto z^{-1}$, the scaling of Terray et al. (1996) who found a transitional layer with $\epsilon \propto z^{-2}$ and the scaling proposed by Huang and Qiao (2010) who use the shear induced by the Stokes drift from surface waves. For the conditions encountered, the wall layer scaling in the mixed layer was within an order of magnitude of our $\epsilon$ estimates with a tendency to overestimate the observed dissipation. Although the scaling of Terray et al. (1996) has been confirmed previously in the ocean with the presence of swell (Drennan et al., 1996; Gerbi et al., 2009) in cases where the wave field could easily be separated into wind and swell components. Results from ASIP, the ultrasonic wave altimeter and the meteorological measurements suggest that the scaling of Terray et al. (1996) does not match the data well for the conditions encountered. This result was also reached in a similar experiment (Greenan et al., 2001) where observations deviated from the Terray et al. (1996) scaling when the sea becomes mixed and there was no clear separation between wind and swell. Our results, early in the deployment when the wind and waves were more constant coinciding well with the exponential depth dependence proposed by Huang and Qiao (2010). However, the scaling proposed by Huang and Qiao (2010) did not agree as well with our observations during the evening with low winds and swell present, nor later in the experiment during the rapid increase in wind speed.

Estimates of the integrated dissipation in the mixed layer indicated that $\approx 1 \%$ of the wind power at $10 \mathrm{~m}$ is dissipated in the mixed layer. This is identical to the results of Oakey and Elliott (1982) and consistent with results that found the theory of a wall layer to hold in the mixed layer (Soloviev et al., 1988).

Understanding how energy is dissipated in the OBL is fundamental to accurate parameterizations of these processes. There has been some excellent advances in modelling $\epsilon$ in the presence of breaking surface gravity waves (Craig and Banner, 1994; Burchard, 2001) and Langmuir circulations (Grant and Belcher, 2009; Teixeira, 2012; Janssen, 2012), but often these models are presented with largely varying empirical coefficients to fit the limited data available. This is especially true in the open ocean where measurements of $\epsilon$ in the upper few meters and free from ship contamination are very hard to obtain.

Due to the intermittent nature of turbulence any scaling law will always have some limitations when comparing snapshots of the turbulent dissipation in the upper mixed layer. Taking this into consideration, along with a dearth of ac- curate dissipation estimates in the mixed layer of the open ocean, make attempts at parameterizing the profile of $\epsilon$ very challenging. More comprehensive data sets under various sea states and conditions are necessary to determine the conditions under which certain scaling can and may hold true.

Acknowledgements. The authors are grateful for funding support from the National Science and Engineering Research Council of Canada, the FP7 grant IRG-224776 and the Research Council of Norway through support from grants 196438 and 207541. We also thank the crew of the R/V Knorr and Scott Miller for his help as chief scientist during the campaign.

Edited by: C. Donlon

\section{References}

Agrawal, Y. C., Terray, E. A., Donelan, M. A., Hwang, P. A., and Williams III, A. J.: Enhanced dissipation of kinetic energy beneath surface waves, Nature, 359, 219-220, 1992.

Anis, A. and Moum, J. M.: Surface Wave-Turbulence Interactions: Scaling $\epsilon(z)$ near the Sea Surface, J. Phys. Oceanogr., 25, 20252045, 1995.

Babanin, A. V. and Haus, B. K.: On the Existence of Water Turbulence Induced by Nonbreaking Surface Waves, J. Phys. Oceanogr., 39, 2675-2679, 2009.

Bouws, E., Draper, L., Shearman, E. D. R., Laing, A. K., Feit, D., Mass, W., Eide, L. I., Francis, P., Carter, D. J. T., and Battjes, J. A.: Guide to Wave analysis and forecasting. WMO-No. 702, World Meteorological Organization, 2nd Edn., 1998.

Burchard, H. L.: Simulating the Wave-Enhanced Layer under Breaking Surface Waves with Two-Equation Turbulence Models, J. Phys. Oceanogr., 31, 3133-3145, 2001.

Christensen, K. H., Röhrs, J., Ward, B., Drivdal, M., and Broström, G.: Surface Wave Measurements Using a Ship Mounted Ultrasonic Altimeter, in: AGU Ocean Sciences Meeting (Salt Lake City, Utah), poster, 2012.

Churchill, J. H. and Csanady, G. T.: Near-Surface Measurements of Quasi-Lagrangian Velocities in Open Water, J. Phys. Oceanogr., 13, 1669-1680, 1983.

Craig, P. D. and Banner, M. L.: Modelling wave-enhanced turbulence in the ocean surface layer, J. Phys. Oceanogr., 24, 25462559, 1994.

de Boyer Montégut, C., Madec, G., Fischer, A. S., Lazar, A., and Iudicone, D.: Mixed layer depth over the global ocean: An examination of profile data and a profile-based climatology, J. Geophys. Res., 109, C12003, doi:10.1029/2006JC004051, 2004.

Dee, D. P., Uppala, S. M., Simmons, A. J., Berrisford, P., Poli, P., Kobayashi, S., Andrae, U., Balmaseda, M. A., Balsamo, G., Bauer, P., Bechtold, P., Beljaars, A. C. M., van de Berg, L., Bidlot, J., Bormann, N., Delsol, C., Dragani, R., Fuentes, M., Geer, A. J., Haimberger, L., Healy, S. B., Hersbach, H., Hólm, E. V., Isaksen, L., Kållberg, P., Köhler, M., Matricardi, M., McNally, A. P., Monge-Sanz, B. M., Morcrette, J. J., Park, B. K., Peubey, C., de Rosnay, P., Tavolato, C., Thépaut, J. N., and Vitart, F.: The ERA-Interim reanalysis: configuration and performance of the data assimilation system, Q. J. Roy. Meteorol. Soc., 137, 553$597,2011$. 
Denman, K. and Gargett, A. E.: Biological-physical interactions in the upper ocean: The role of vertical and small scale transport processes, Annu. Rev. Fluid Mech., 27, 225-255, 1989.

Dillon, T. M., Richman, J. G., Hansen, C. G., and Pearson, M. D.: Near-surface turbulence measurements in a lake, Nature, 290, 390-392, 1981.

Drennan, W. M., Donelan, M. A., Terray, E. A., and Katsaros, K. B.: Ocean Turbulence Dissipation Measurements in SWADE, J. Phys. Oceanogr., 26, 808-815, 1996.

Efron, B. and Gong, G.: A leisurely look at the bootstrap, the jacknife and cross-validation, Am. Stat., 37, 36-48, 1983.

Fairall, C. W., Bradley, E. F., Rogers, D. P., Edson, J. B., and Young, G. S.: Bulk parameterization of air-sea fluxes for Tropical OceanGlobal Atmosphere Coupled-Ocean Atmosphere Response Experiment, J. Geophys. Res., 101, 3747-3764, 1996.

Fairall, C. W., Bradley, E. F., Hare, J. E., Grachev, A. A., and Edson, J. B.: Bulk Parameterization of Air-Sea Fluxes: Updates and Verification for the COARE Algorithm, J. Climate, 16, 571-591, 2003.

Gargett, A. E.: Ocean Turbulence, Annu. Rev. Fluid Mech., 21, 419-451, 1989.

Garrett, C.: Processes in the surface mixed layer of the ocean, Dynam. Atmos. Oceans, 23, 19-34, 1996.

Gerbi, G. P., Trowbridge, J. H., Terray, E. A., Plueddemann, A. J., and Kukulka, T.: Observations of Turbulence in the Ocean Surface Boundary Layer: Energetics and Transport, J. Phys. Oceanogr., 39, 1077-1096, 2009.

Grant, A. L. and Belcher, S. E.: Characteristics of Langmuir Turbulence in the Ocean Mixed Layer, J. Phys. Oceanogr., 39, 18711887, 2009.

Greenan, B. J., Oakey, N. S., and Dobson, F. W.: Estimates of Dissipation in the Ocean Mixed Layer Using a Quasi-Horizontal Microstructure Profiler, J. Phys. Oceanogr., 31, 992-1004, 2001.

Huang, C. J. and Qiao, F.: Wave-turbulence interaction and its induced mixing in the upper ocean, J. Geophys. Res., 115, c04026, doi:10.1029/2009JC005853, 2010.

Janssen, P. A. E. M.: Ocean wave effects on the daily cycle in SST, J. Geophys. Res., 117, C00J32, doi:10.1029/2012JC007943, 2012.

Jones, I. S. F. and Kenney, B. C.: The scaling of vertical velocity fluctutations in the surface mixed layer, J. Geophys. Res., 82, 1392-1396, 1977.

Kitaigorodskii, S. A., Donelan, M. A., Lumley, J. L., and Terray, E. A.: Wave-turbulence interactions in the upper ocean: Part II, J. Phys. Oceanogr., 13, 1988-1999, 1983.

Lorke, A. and Peeters, F.: Toward a unified scaling relation for interfacial fluxes, J. Phys. Oceanogr., 36, 955-961, 2006.

Macoun, P. and Lueck, R.: Modelling the spatial response of the airfoil shear probe using different sized probes, J. Atmos. Ocean. Tech., 21, 284-297, 2004.

McWilliams, J. C., Sullivan, P. P., and Moeng, C. H.: Langmuir turbulence in the ocean, J. Fluid Mech., 334, 1-30, 1997.

Moum, J. N., Gregg, M. C., Lien, R. C., and Carr, M. E.: Comparison of Turbulence Kinetic Energy Dissipation Rate Estimates from Two Ocean Microstructure Profilers, J. Phys. Oceanogr., 12, 346-366, 1995.

Noh, Y., Min, H. S., and Raasch, S.: Large Eddy Simulation of the Ocean Mixed Layer: The Effect of Wave Breaking and Langmuir Circulation, J. Phys. Oceanogr., 34, 720-735, 2004.
Oakey, N. S. and Elliott, J. A.: Dissipation within the surface mixed layer, J. Phys. Oceanogr., 12, 171-185, 1982.

Osborn, T. R.: Vertical profiling of velocity microstructure, J. Phys. Oceanogr., 4, 109-115, 1974.

Osborn, T. R.: Estimates of the local rate of vertical diffusion from dissipation measurements, J. Phys. Oceanogr., 10, 83-89, 1980.

Osborn, T. R., Farmer, D. M., abd S A Thorpe, S. V., and Cure, M.: Measurements of bubble plumes and turbulence froma submarine, Atmos. Ocean, 30, 419-440, 1992.

Richman, J. and Garrett, C.: The transfer of energy and momentum by the wind to the surface mixed layer, J. Phys. Oceanogr., 7, 876-881, 1977.

Soloviev, A. V., Vershinsky, N. V., and Bezverchnii, V. A.: Small scale turbulence measurements in the thin surface layer of the ocean, Deep-Sea Res., 35, 1859-1874, 1988.

Stevens, C. L. and Smith, M. J.: Temperature Microstructure beneath Surface Gravity Waves, J. Atmos. Ocean. Tech., 21, 17471757, 2004.

Stevens, C., Ward, B., Law, C., and Walkington, M.: Surface layer mixing during the SAGE ocean fertilization experiment, DeepSea Res. Pt. II, 58, 776-785, 2011.

Stewart, R. W. and Grant, H. L.: Determination of the rate of dissipation of turbulent energy near the sea surface in the presence of waves, J. Geophys. Res., 67, 3177-3180, 1962.

Stips, A., Burchard, H., Bolding, K., Prandke, H., Simon, A., and Wüest, A.: Measurement and simulation of viscous dissipation in the wave affected surface layer, Deep-Sea Res. Pt. II, 52, 1133 $1155,2005$.

Teixeira, M. A. C.: The influence of Langmuir turbulence on the scaling for the dissipation rate in the oceanic boundary layer, J. Geophys. Res., 117, C05015, doi:10.1029/2011JC007235, 2012.

Terray, E. A., Donelan, M. A., Agrawal, Y. C., Drennan, W. M., Kahma, K. K., Williams III, A. J., Hwang, P. A., and Kitaigorodskii, S. A.: Estimates of Kinetic Energy Dissipation under Breaking Waves, J. Phys. Oceanogr., 26, 792-807, 1996.

Thomson, R. E. and Fine, I. V.: Estimating Mixed Layer Depth from Oceanic Profile Data, J. Phys. Oceanogr., 20, 319-329, 2003.

Ward, B. and T. Fristedt, Air-Sea Interaction Profiler: Autonomous Upper Ocean Measurements, in Proceedings of the 3rd US/EUBaltic International Symposium, Talinn, May, 2008.

Wüest, A., Piepke, G., and Van Senden, D.: Turbulent kinetic energy balance as a tool for estimating vertical diffusivity in wind-forced stratified waters, Limnol. Oceanogr., 45, 1388-1400, 2000.

Yamazaki, H., Osborn, T., and Squires, K. D.: Direct numerical simulation of planktonic contact in turbulent flow, J. Plankton Res., 13, 629-643, 1991.

Zappa, C. J., McGillis, W. R., Raymond, P. A., Edson, J. B., Hintsa, E. J., Zemmelink, H. J., Dacey, J. W. H., and Ho, D. T.: Environmental turbulent mixing controls of air-water gas exchange in marine and aquatic systems, Geophys. Res. Lett., 34, 110601, doi:10.1029/2006GL028790, 2007.

Zhang, H. M. and Talley, L. D.: Heat and buoyancy budgets and mixing rates in the Indian and global Oceans, J. Phys. Oceanogr., 28, 1961-1978, 1998. 